\title{
Effect of Growing Medias on Different Varieties of Oriental Lilium (Lilium orientalis) under Shadenet in Allahabad Agro Climatic Conditions
}

\author{
Upesh Chandrakar, Urfi Fatmi, Swapnil Bharti* and Sadhana Swastika \\ Department of Horticulture, Naini Agricultural Institute, Sam Higginbottom University of \\ Agriculture, Technology and Sciences, Allahabad-211007, India \\ *Corresponding author
}

\section{A B S T R A C T}

\section{Keywords \\ Oriental lilium, Bulb, Growing Media, \\ Vermicompost, \\ Coco peat, Sand \\ Article Info \\ Accepted: \\ 15 November 2018 \\ Available Online: \\ 10 December 2018}

\begin{abstract}
The present investigation was under taken in the Department of Horticulture, Naini Agricultural Institute, Sam Higginbottom University of Agriculture, Technology and Sciences, Allahabad during rabi season (2016-2017). Experiment was carried out to assess the performance of five Oriental lily varieties viz., Cobra Red, Signum, Yelloween, Sorbonne and Justina grown in different media viz. vermicompost, coco peat and sand in different compositions. The study was conducted as a pot culture trial in form of factorial experiment following completely Randomized Design with 3 replications. The study revealed that the plant height, number of leaves, days taken for $1^{\text {st }}$ flower bud initiation, length of $1^{\text {st }}$ matured flower bud (mm), diameter of fully open $1^{\text {st }}$ flower $(\mathrm{mm})$, number of flowers per plant were found to be significant and they were found to be maximum in the media containing equal proportions of coco peat: vermicompost: soil: $(1: 1: 1 \mathrm{v} / \mathrm{v})$.
\end{abstract}

\section{Introduction}

Lilium is cultivated worldwide and is one of the horticulturally most important genera for cut flower, pot plant and garden plant. It is one among the important bulbous plants belonging to family Liliaceae and is commercially grown in India for cut flowers. It is widely acclaimed for its use as cut flowers and pot plants and has been admired for its aesthetic beauty and a symbol of purity and regality. They have a very good demand in the flower market as cut flower and pot plants. They are of special economic importance because they posses big, beautiful and attractive flowers. This plant possesses the $7^{\text {th }}$ position among the cut flowers of the world (Varshney et al., 2000) and occupies fourth position after rose, tulip, and spray chrysanthemum for total sales.

Oriental lilies (Lilium orientalis) are the classic late bloomers that bloom after Asiatic lilies in late summer when most other bulbs have long finished and grow from 2 to 6 feet tall and offer pretty speckled large flowers with heavy fragrance. The colourful flowers produce large amounts of nectar and pollen that attract insects which pollinate them. Orientals blooms are white, yellow and pink with a different colour on their rims or with a combination of two or three colour. 
Lilies could be forced in various kinds of soils, however growing medium should be well aerated, with good water holding capacity, good drainage and good physical structure. In heavy soils without enough drainage, the development of root system is suppressed and plants are more susceptible to soil borne diseases (Beattie and White, 1992).

Due to high requirements of nutrient for the growth of lilium, growers very often use pots instead of planting bulbs directly into the soil on greenhouse beds. Therefore it is important that the growing media selected for planting of lilium bulbs should provide all the necessary attributes for its proper growth and development. Thus the aim of this study is to examine the effect of sand, coco peat and vermicompost as a growing medium on the lily growth and quality.

Sand is a naturally occurring granular material composed of finely divided rock and mineral particles. They are often dry, nutrient deficient and fast-draining. They have little or no ability to transport water from deeper layers through capillary transport. Thus it helps in proper drainage and there are no chances of water logging conditions.

Coco peat, also known as coir dust or coconut mesocarp, has been considered as a renewable sphagnum peat substitute for the use in horticulture (Yau and Murphy, 2000 Pickering, 1997).

Due to low levels of nutrients in its composition, coco peat is usually not the sole component in the medium used to grow plants. It has a good physical properties, high total pore space, high water content, low shrinkage, low bulk density, high water holding capacity and has around 1000 times more air than soil. It is considered as a good growing media component with acceptable $\mathrm{pH}$, electrical conductivity and other chemical attributes. Vermicomposts are produced through interactions between earthworms and microorganisms in the breakdown of organic wastes (Edwards et al., 2010). Depending on the origin, vermicomposts differ in chemical composition (Handreck, 1986). Vermicomposts are finely divided peat-like materials with high porosity, aeration, drainage, and water-holding capacity.

\section{Materials and Methods}

The experiment was laid out in Factorial Completely Randomized design (FCRD) with three replications. The treatments in each replication were allotted randomly. Thirty treatments having five varieties were tried in the experimental design.

\section{Experimental site and duration}

The present study was conducted in shade net at Department of Horticulture, Naini Agricultural Institute, Sam Higginbottom University of Agriculture, Technology and Sciences, Allahabad during rabi season of 2016-2017 from November to March.

\section{Experimental design}

$5 \times 6(5$ varieties $\times 6$ media combinations) factorial experiment was laid out in a Factorial Completely Randomized Design with 3 replications.

\section{Treatments of the experiment}

Oriental Lilium variety $\left(\mathrm{V}_{1}\right.$ :Cobra Red; $\mathrm{V}_{2}$ :Signum; $\mathrm{V}_{3}$ :Yelloween; V4:Sorbonne; $\mathrm{V}_{5}$ : Justina) and media combinations $\left(\mathrm{M}_{0}\right.$ : Garden soil; $\mathrm{M}_{1}$ : One part of vermicompost + one part of cocopeat + one part of sand $(1: 1: 1, \mathrm{v} / \mathrm{v})$; $\mathrm{M}_{2}$ : Two parts of vermicompost + one part of cocopeat + one part of sand $(2: 1: 1, \mathrm{v} / \mathrm{v}) ; \mathrm{M}_{3}$ : One part of vermicompost, + two parts of cocopeat + One Part of sand (1:2:1, v/v); $\mathrm{M}_{4}$ : One part of vermicompost, +twopart of cocopeat + two part of sand $(1: 1: 2, \mathrm{v} / \mathrm{v}) ; \mathrm{M}_{5}$ : 
Two part of vermicompost + two parts of cocopeat + one part of sand $(2: 2: 1, \mathrm{v} / \mathrm{v})$ were used in the experiment.

\section{Pot size}

The size of pot was 12 inch which earthen pots which had a hole at bottom surface for proper drainage and were place $5 \mathrm{~cm}$ sand surface.

\section{Pre planting operations}

Each media was treated with $0.2 \%$ of 20 E.C. chloropyriphos for termite control followed by $0.2 \%$ of Bavastin solution and the media was kept under shade to air dry for night. Six different potting media with different compositions by volume were prepared including garden soil as a control. The bulbs were soaked in Bavistin solution (0.2\%) for half an hour and then spread on newspaper to air dry for a night

\section{Planting of the bulbs}

The bulbs were planted in 12 inch earthern pots at a depth of 6-8 inches

\section{Results and Discussion}

\section{Vegetative parameters}

\section{Plant height}

Interaction effect revealed that maximum plant height $(77.40 \mathrm{~cm})$ was recorded in $\mathrm{T}_{14}\left(\mathrm{~V}_{3} \mathrm{M}_{1}\right)$ Yelloween variety of Oriental lilium when grown in vermicompost + cocopeat + sand $(1: 1: 1 \mathrm{v} / \mathrm{v})$ followed by $T_{2}$ $\left(\mathrm{V}_{1} \mathrm{M}_{1}\right)$ when plant height was recorded as $(70.27 \mathrm{~cm})$ when Cobra Red variety of Oriental lilium when grown in vermicompost + cocopeat + sand $(1: 1: 1 \mathrm{v} / \mathrm{v})$ and the minimum plant height $(36.37 \mathrm{~cm})$ was recorded in $\mathrm{T}_{7}\left(\mathrm{~V}_{2} \mathrm{M}_{0}\right)$ Signum variety of Oriental lilium when grown in garden soil (control). The plant height was found to be greatest in $M_{1}$
(Vermicompost + coco peat + sand, $1: 1: 1 \mathrm{v} / \mathrm{v})$ which was due to balanced nutrient availability and good water holding capacity and porosity of media (Table 1).

\section{Number of leaves}

Interaction effect revealed that maximum number of leaves per plant (82.80) was recorded in $\mathrm{T}_{14}\left(\mathrm{~V}_{3} \mathrm{M}_{1}\right)$, followed by $\mathrm{T}_{8}$ $\left(\mathrm{V}_{2} \mathrm{M}_{1}\right)$ when number of leaves was recorded as (40.97). The minimum number of leaves (16.40) was recorded in $\mathrm{T}_{25} \quad\left(\mathrm{~V}_{5} \mathrm{M}_{0}\right)$. Maximum number of leaves was observed in $\mathrm{M}_{1}$ (Vermicompost + coco peat + sand, $1: 1: 1 \mathrm{v} / \mathrm{v})$ which might be due to positive Effect on vegetative growth of plant because of good physical and biological condition of coco peat and induced metabolic processes which leads to stimulated photosynthesis and increased leaf mass because of vermicompost (Table 2).

\section{Floral parameters}

\section{Number of days taken for bud emergence}

Interaction effect revealed that minimum number of days taken for $1^{\text {st }}$ flower bud initiation (28.93) was recorded in $\mathrm{T}_{8}\left(\mathrm{~V}_{2} \mathrm{M}_{1}\right)$, followed by $\mathrm{T}_{2}\left(\mathrm{~V}_{1} \mathrm{M}_{1}\right)$ when number of days taken was recorded as (30.63).The maximum number of days taken for $1^{\text {st }}$ flower bud initiation (42.73) was recorded in $\mathrm{T}_{1}\left(\mathrm{~V}_{1} \mathrm{M}_{0}\right)$. The number of days required for $1^{\text {st }}$ flower bud initiation was found to be minimum which may be due to more number of leaves which leads to stimulated photosynthesis and induced morphological changes (Table 3 ).

\section{Bud length}

Interaction effect revealed that maximum $1^{\text {st }}$ flower bud length $(132.50 \mathrm{~mm})$ was recorded in $\mathrm{T}_{26}\left(\mathrm{~V}_{5} \mathrm{M}_{1}\right)$, followed by $\mathrm{T}_{30}\left(\mathrm{~V}_{5} \mathrm{M}_{5}\right)$ when length of $1^{\text {st }}$ flower bud was recorded as (130.77mm). 
Table.1 Effect of growing media on different varieties of oriental lilium on plant height (cm) at 60 DAP

\begin{tabular}{|c|c|c|c|c|c|c|}
\hline & \multicolumn{6}{|c|}{ Plant height $(\mathrm{cm})$ at 60 DAP } \\
\hline \multirow[t]{2}{*}{ Media (M) } & \multicolumn{6}{|c|}{ Varieties (V) } \\
\hline & $\mathbf{V}_{1}$ & $\mathbf{V}_{2}$ & $\mathbf{V}_{3}$ & $\mathbf{V}_{4}$ & $\mathbf{V}_{5}$ & Mean $(M)$ \\
\hline $\mathrm{M}_{0}$ & 47.13 & 36.37 & 58.93 & 49.77 & 39.77 & 46.39 \\
\hline $\mathrm{M}_{1}$ & 70.27 & 63.33 & 77.40 & 68.80 & 60.90 & 68.14 \\
\hline $\mathrm{M}_{2}$ & 60.73 & 47.77 & 70.37 & 61.53 & 49.83 & 58.05 \\
\hline $\mathrm{M}_{3}$ & 63.90 & 53.03 & 72.03 & 64.63 & 53.73 & 61.47 \\
\hline $\mathrm{M}_{4}$ & 56.67 & 44.73 & 65.70 & 56.60 & 46.00 & 53.94 \\
\hline $\mathrm{M}_{5}$ & 67.10 & 57.20 & 74.57 & 66.33 & 56.20 & 64.28 \\
\hline Mean (V) & 60.97 & 50.41 & 69.83 & 61.28 & 51.07 & \\
\hline \multicolumn{2}{|c|}{ Comparison } & \multicolumn{2}{|c|}{ C. D. at $5 \%$} & \multicolumn{2}{|c|}{ S.Ed. ( \pm$)$} & F test \\
\hline \multicolumn{2}{|c|}{ Due to Varieties } & \multicolumn{2}{|c|}{0.69} & \multicolumn{2}{|c|}{0.35} & $\mathbf{S}$ \\
\hline \multicolumn{2}{|c|}{ Due to Media } & \multicolumn{2}{|c|}{0.76} & \multicolumn{2}{|c|}{0.38} & $\mathbf{S}$ \\
\hline \multicolumn{2}{|c|}{ Inter $(\mathbf{V} \times \mathbf{M})$} & \multicolumn{2}{|c|}{1.70} & \multicolumn{2}{|c|}{0.85} & $\mathbf{S}$ \\
\hline
\end{tabular}

Table.2 Effect of growing media on different varieties of oriental lilium on number of leaves per plant at $60 \mathrm{DAP}$

\begin{tabular}{|c|c|c|c|c|c|c|}
\hline & \multicolumn{6}{|c|}{ Number of leaves per plant at 60 DAP } \\
\hline \multirow[t]{2}{*}{ Media (M) } & \multicolumn{6}{|c|}{ Varieties (V) } \\
\hline & $\mathbf{V}_{1}$ & $\mathbf{V}_{2}$ & $\mathbf{V}_{3}$ & $\mathbf{V}_{4}$ & $\mathbf{V}_{5}$ & Mean (M) \\
\hline $\mathrm{M}_{0}$ & 21.60 & 21.70 & 66.40 & 22.90 & 16.40 & 29.80 \\
\hline $\mathrm{M}_{1}$ & 34.30 & 40.97 & 82.80 & 38.23 & 25.93 & 44.45 \\
\hline $\mathrm{M}_{2}$ & 26.20 & 30.27 & 73.70 & 28.13 & 19.97 & 35.65 \\
\hline $\mathrm{M}_{3}$ & 29.50 & 33.30 & 76.37 & 29.67 & 21.40 & 38.05 \\
\hline $\mathrm{M}_{4}$ & 24.03 & 27.90 & 70.20 & 26.57 & 18.53 & 33.45 \\
\hline $\mathrm{M}_{5}$ & 31.33 & 36.00 & 78.97 & 34.07 & 23.40 & 40.75 \\
\hline Mean (V) & 27.83 & 31.69 & 74.74 & 29.93 & 20.94 & \\
\hline \multicolumn{2}{|c|}{ Comparison } & \multicolumn{2}{|c|}{ C. D. at $5 \%$} & \multicolumn{2}{|c|}{ S.Ed. ( \pm$)$} & F test \\
\hline \multicolumn{2}{|c|}{ Due to Varieties } & \multicolumn{2}{|c|}{0.60} & \multicolumn{2}{|c|}{0.30} & $\mathbf{S}$ \\
\hline \multicolumn{2}{|c|}{ Due to Media } & \multicolumn{2}{|c|}{0.66} & \multicolumn{2}{|c|}{0.33} & $\mathbf{S}$ \\
\hline \multicolumn{2}{|c|}{ Inter $(\mathbf{V} \times \mathbf{M})$} & \multicolumn{2}{|c|}{1.47} & \multicolumn{2}{|c|}{0.74} & $\mathbf{S}$ \\
\hline
\end{tabular}


Table.3 Effect of growing media on different varieties of oriental lilium on days taken for first flower bud emergence

\begin{tabular}{|c|c|c|c|c|c|c|}
\hline & \multicolumn{6}{|c|}{ Days taken for $1^{\text {st }}$ bud emergence } \\
\hline \multirow[t]{2}{*}{ Media (M) } & \multicolumn{6}{|c|}{ Varieties (V) } \\
\hline & $\mathbf{V}_{1}$ & $\mathbf{V}_{2}$ & $\mathbf{V}_{3}$ & $\mathbf{V}_{4}$ & $\mathbf{V}_{5}$ & Mean (M) \\
\hline $\mathrm{M}_{0}$ & 42.73 & 38.63 & 41.33 & 41.23 & 42.20 & 41.23 \\
\hline $\mathrm{M}_{1}$ & 30.63 & 28.93 & 31.70 & 31.77 & 34.07 & 31.42 \\
\hline $\mathrm{M}_{2}$ & 35.73 & 33.67 & - & 36.80 & 38.27 & 36.12 \\
\hline $\mathrm{M}_{3}$ & 33.27 & 31.83 & - & 34.77 & 36.50 & 34.09 \\
\hline $\mathrm{M}_{4}$ & 39.03 & 34.87 & - & 38.50 & 39.40 & 37.95 \\
\hline $\mathrm{M}_{5}$ & 31.60 & 30.70 & 33.60 & 33.30 & 35.87 & 33.01 \\
\hline Mean (V) & 35.50 & 33.11 & 35.54 & 36.06 & 37.72 & \\
\hline \multicolumn{2}{|c|}{ Comparison } & \multicolumn{2}{|c|}{ C. D. at $5 \%$} & \multicolumn{2}{|c|}{ S.Ed. $( \pm)$} & F test \\
\hline \multicolumn{2}{|c|}{ Due to Varieties } & \multicolumn{2}{|c|}{0.42} & \multicolumn{2}{|c|}{0.21} & $\mathbf{S}$ \\
\hline \multicolumn{2}{|c|}{ Due to Media } & \multicolumn{2}{|c|}{0.46} & \multicolumn{2}{|c|}{0.23} & $\mathbf{S}$ \\
\hline \multicolumn{2}{|c|}{ Inter (V x M) } & \multicolumn{2}{|c|}{1.04} & \multicolumn{2}{|c|}{0.52} & $\mathbf{S}$ \\
\hline
\end{tabular}

Table.4 Effect of growing media on different varieties of oriental lilium on Length of first flower bud $(\mathrm{mm})$

\begin{tabular}{|c|c|c|c|c|c|c|}
\hline & \multicolumn{6}{|c|}{ Length of $1^{\text {st }}$ flower bud (mm) } \\
\hline \multirow[t]{2}{*}{ Media (M) } & \multicolumn{6}{|c|}{ Varieties (V) } \\
\hline & $\mathbf{V}_{1}$ & $\mathbf{V}_{2}$ & $\mathbf{V}_{3}$ & $\mathbf{V}_{4}$ & $\mathbf{V}_{5}$ & Mean (M) \\
\hline $\mathrm{M}_{0}$ & 70.90 & 97.80 & 95.63 & 96.40 & 112.23 & 94.59 \\
\hline $\mathrm{M}_{1}$ & 98.17 & 116.67 & 110.47 & 112.30 & 132.50 & 114.02 \\
\hline $\mathrm{M}_{2}$ & 82.30 & 106.30 & - & 102.40 & 121.70 & 103.18 \\
\hline $\mathrm{M}_{3}$ & 93.20 & 111.23 & - & 107.23 & 127.87 & 109.88 \\
\hline $\mathrm{M}_{4}$ & 76.07 & 102.77 & - & 100.77 & 118.17 & 99.44 \\
\hline $\mathrm{M}_{5}$ & 95.63 & 114.20 & 102.07 & 110.67 & 130.77 & 110.67 \\
\hline Mean (V) & 86.04 & 108.16 & 102.72 & 104.96 & 123.87 & \\
\hline \multicolumn{2}{|c|}{ Comparison } & \multicolumn{2}{|c|}{ C. D. at $5 \%$} & \multicolumn{2}{|c|}{ S.Ed. $( \pm)$} & F test \\
\hline \multicolumn{2}{|c|}{ Due to Varieties } & \multicolumn{2}{|c|}{0.42} & \multicolumn{2}{|c|}{0.21} & $\mathbf{S}$ \\
\hline \multicolumn{2}{|c|}{ Due to Media } & \multicolumn{2}{|c|}{0.46} & \multicolumn{2}{|c|}{0.23} & $\mathbf{S}$ \\
\hline \multicolumn{2}{|c|}{ Inter (V $\times$ M) } & \multicolumn{2}{|c|}{1.02} & \multicolumn{2}{|c|}{0.51} & $\mathbf{S}$ \\
\hline
\end{tabular}


Table.5 Effect of growing media on different varieties of oriental lilium on diameter of fully open first flower (mm)

\begin{tabular}{|c|c|c|c|c|c|c|}
\hline & \multicolumn{6}{|c|}{ Diameter of fully open $1^{\text {st }}$ flower $(\mathrm{mm})$} \\
\hline \multirow[t]{2}{*}{ Media (M) } & \multicolumn{6}{|c|}{ Varieties (V) } \\
\hline & $\mathbf{V}_{1}$ & $\mathbf{V}_{2}$ & $\mathbf{V}_{3}$ & $\mathbf{V}_{4}$ & $\mathbf{V}_{5}$ & Mean $(M)$ \\
\hline $\mathrm{M}_{0}$ & 107.13 & 202.73 & 138.13 & 155.27 & 221.37 & 164.93 \\
\hline $\mathrm{M}_{1}$ & 168.57 & 253.37 & 152.33 & 222.10 & 299.90 & 219.25 \\
\hline $\mathrm{M}_{2}$ & 146.43 & 226.17 & - & 188.03 & 275.97 & 209.15 \\
\hline $\mathrm{M}_{3}$ & 154.07 & 234.53 & - & 198.30 & 287.70 & 218.65 \\
\hline $\mathrm{M}_{4}$ & 121.63 & 218.13 & - & 178.87 & 249.93 & 192.14 \\
\hline $\mathrm{M}_{5}$ & 162.50 & 242.47 & 148.70 & 211.63 & 294.97 & 212.05 \\
\hline Mean (V) & 143.39 & 229.57 & 146.39 & 192.37 & 271.64 & \\
\hline \multicolumn{2}{|c|}{ Comparison } & \multicolumn{2}{|c|}{ C. D. at $5 \%$} & \multicolumn{2}{|c|}{ S.Ed. $( \pm)$} & F test \\
\hline \multicolumn{2}{|c|}{ Due to Varieties } & \multicolumn{2}{|c|}{1.19} & \multicolumn{2}{|c|}{0.60} & $\mathbf{S}$ \\
\hline \multicolumn{2}{|c|}{ Due to Media } & \multicolumn{2}{|c|}{1.31} & \multicolumn{2}{|c|}{0.65} & $\mathbf{S}$ \\
\hline \multicolumn{2}{|c|}{ Inter $(\mathbf{V} \times \mathbf{M})$} & \multicolumn{2}{|c|}{2.92} & \multicolumn{2}{|c|}{1.46} & $\mathbf{S}$ \\
\hline
\end{tabular}

Table.6 Effect of growing media on different varieties of oriental lilium on number of flowers per plant

\begin{tabular}{|c|c|c|c|c|c|c|}
\hline & \multicolumn{6}{|c|}{ Number of flowers per plant } \\
\hline \multirow[t]{2}{*}{ Media (M) } & \multicolumn{6}{|c|}{ Varieties (V) } \\
\hline & $\mathbf{V}_{1}$ & $\mathbf{V}_{2}$ & $\mathbf{V}_{\mathbf{3}}$ & $\mathbf{V}_{4}$ & $\mathbf{V}_{5}$ & Mean $(\mathbf{M})$ \\
\hline $\mathrm{M}_{0}$ & 1.93 & 1.03 & 1.33 & 1.87 & 1.87 & 1.61 \\
\hline $\mathrm{M}_{1}$ & 3.77 & 2.13 & 3.83 & 3.27 & 3.27 & 3.25 \\
\hline $\mathrm{M}_{2}$ & 2.77 & 1.30 & - & 2.33 & 2.30 & 2.18 \\
\hline $\mathrm{M}_{3}$ & 3.00 & 1.53 & - & 2.83 & 2.53 & 2.47 \\
\hline $\mathrm{M}_{4}$ & 2.33 & 1.20 & - & 2.13 & 2.07 & 1.93 \\
\hline $\mathrm{M}_{5}$ & 3.33 & 1.83 & 2.97 & 3.07 & 2.80 & 2.80 \\
\hline Mean (V) & 2.86 & 1.51 & 2.71 & 2.58 & 2.47 & \\
\hline \multicolumn{2}{|c|}{ Comparison } & \multicolumn{2}{|c|}{ C. D. at $5 \%$} & \multicolumn{2}{|c|}{ S.Ed. ( \pm$)$} & F test \\
\hline \multicolumn{2}{|c|}{ Due to Varieties } & \multicolumn{2}{|c|}{0.07} & \multicolumn{2}{|c|}{0.03} & $\mathbf{S}$ \\
\hline \multicolumn{2}{|c|}{ Due to Media } & \multicolumn{2}{|c|}{0.07} & \multicolumn{2}{|c|}{0.04} & $\mathbf{S}$ \\
\hline \multicolumn{2}{|c|}{ Inter $(\mathbf{V} \times \mathbf{M})$} & \multicolumn{2}{|c|}{0.16} & \multicolumn{2}{|c|}{0.08} & $\mathbf{S}$ \\
\hline
\end{tabular}


The 1st flower bud length $(70.90 \mathrm{~mm})$ was recorded in $\mathrm{T}_{1}\left(\mathrm{~V}_{1} \mathrm{M}_{0}\right)$. Bud length depends on variety and number of buds on the stem. Plants bearing more flowers are usually having shorter bud length. Similar findings were reported by Treder (2008).

\section{Diameter of fully open $1^{\text {st }}$ flower}

Interaction effect revealed that maximum diameter of $1^{\text {st }}$ fully opened flower (299.90mm) was recorded in $\mathrm{T}_{26}\left(\mathrm{~V}_{5} \mathrm{M}_{1}\right)$, Justina variety of Oriental lilium when grown in one part of vermicompost + one part of cocopeat + one part of sand. $(1: 1: 1 \mathrm{v} / \mathrm{v})$ followed by $\mathrm{T}_{30}\left(\mathrm{~V}_{5} \mathrm{M}_{5}\right)$ when diameter of $1^{\text {st }}$ fully opened flower was recorded as $(294.97 \mathrm{~mm})$, Signum variety of Oriental lilium when grown in two part of vermicompost + two part of cocopeat + one part of sand. $(2: 2: 1 \mathrm{v} / \mathrm{v})$.

The minimum diameter of $1^{\text {st }}$ fully opened flower $(107.13 \mathrm{~mm})$ was recorded in $\mathrm{T}_{1}\left(\mathrm{~V}_{1} \mathrm{M}_{0}\right)$ when Cobra Red variety of Oriental lilium was grown in garden soil (control).

The varietal difference with respect to diameter of $1^{\text {st }}$ fully opened flower was observed can be attributed to the genetic makeup of the varieties (Hemlata et al., 1992) and the environmental conditions prevailing during the growth period as well as more number of buds per plant which would result in less flower diameter (Table 4 and 5).

\section{Yield parameters}

\section{Number of flowers per plant}

Interaction effect revealed that maximum number of flowers per plant (3.83) was recorded in $\mathrm{T}_{14}\left(\mathrm{~V}_{3} \mathrm{M}_{1}\right)$ followed by $\mathrm{T}_{8}\left(\mathrm{~V}_{2} \mathrm{M}_{1}\right)$ when number of flowers per plant was recorded as (2.13). The minimum number of flowers (1.03) was recorded in $\mathrm{T}_{7}\left(\mathrm{~V}_{2} \mathrm{M}_{0}\right)$.
The difference in the number of flowers per plant might be due to varieties and genetic potential as well as conditions provided for growth as well as due to better plant growth resulting maximum production and utilization of photo assimilates (Table 6).

\section{Acknowledgement}

We authors are greatly thankful to other professors and members, Department of Horticulture, Naini Agricultural Institute, for their guidance and support during the research trail and also thankful to Department of Agrometrology for providing me with all the weather data throughout my research period and also to the Department of Soil Science for allowing me to perform my lab experiments.

\section{References}

Beattie D.J. and White J.W. 1992. Lilium hybrids and species. In: De Hertogh A.A. and Le Nard M. (Eds.) the Physiology of Flower Bulbs. Elsevier, Amsterdam.

Edwards, C.A., Arancon, N.Q., VaskoBennett, M., Askar, A., Keene, G. 2010. Effect of aqueous extracts from vermicomposts on attacks by cucumber beetles (Acalym navittatum) (Fabr.) On cucumbers and tobacco hornworm (Manduca sexta) (L.) on tomatoes. Pedobiologia, 53(2): 141148.

Handreck, K.A. 1986. Vermicomposts as components of potting media. Bio Cycle, 22 (9): 58-62.

Hemlata, Barigidad, Patil, A. A. and Nalwadi, U. G. 1992. Variability studies in chrysanthemum.

Progressive Horticulture. 24(1-2): 55-59.

Pickering, J.S. 1997. An alternative to peat. The Garden, 22: 428-429.

Treder, J. (2008). The Effect of Cocopeat and Fertilizer on the Growth and 
Flowering of Oriental Lily 'Star Gazer'. Journal of Fruit and Ornamental Plant Research, 16: 361370.

Varshney, A., Srivastava, P.S. and Dhawan, V. 2001. Effect of doses of nitrogen, phosphorus and potassium on the performance of in-vitro propagated bulblets of lilium sp (Asiatic sp). Current Science. 81(10): 1296-1298

Yau, P.Y., Murphy, R.J. 2000. Biodegraded cocopeat as a horticultural substrate. Acta Horticulture, 517: 275-278.

\section{How to cite this article:}

Upesh Chandrakar, Urfi Fatmi, Swapnil Bharti and Sadhana Swastika. 2018. Effect of Growing Medias on Different Varieties of Oriental Lilium (Lilium orientalis) under Shadenet in Allahabad Agro Climatic Conditions. Int.J.Curr.Microbiol.App.Sci. 7(12): 2114-2121. doi: https://doi.org/10.20546/ijcmas.2018.712.240 